\title{
A EXPERIÊNCIA NA CONSTRUÇÃO DE UM CORPO ARTÍSTICO: uma leitura a partir de Derrida e Deleuze
}

\author{
The experience in the construction of an \\ artistic body: Derrida and Deleuze readings
}

\author{
Fernando Machado Silva
}

Mestre em Literatura e Poética Comparada. Universidade de Évora. Professor Assistente da Universidade de Évora. Évora-Portugal, e-mail: fernandomachadosilva79@gmail.com

\begin{abstract}
Resumo
O presente trabalho procura estabelecer uma estratégia de investigação no cruzamento entre a filosofia e a teoria teatral e da performance, ainda por se realizar em Portugal. Nesse sentido e partindo de Jacques Derrida e de Gilles Deleuze, centralizou-se esta pesquisa à volta da noção de Corpo e Experiência, sublinhando a importância de conceitos como différance para a conceptualização do conceito, para nós importante, de Somatografia e explicitação da questão de identidade -, Corpo sem Órgãos - produção de um corpo aberto a todas as possibilidades criativas, bem como ponto de partida para o trabalho do actor/performer -, Devir-potências expressivas, linhas de fuga a percorrer na construção do Corpo sem Órgãos. Por outro lado, pensando a noção de psyché-physys em conjunto com os conceitos expostos, propõe-se um novo entendimento da relação corpo/texto no actor/ performer em oposição à construção psicológica de personagens.
\end{abstract}

Palavras-chave: Teatro/performance; Experiência; Différance; Corpo sem órgãos; Devir. 


\section{Abstract}

The present essay tries to establish an investigation strategy in the confluence of philosophy, theatrical and performance theory, yet to accomplish in Portugal. Thus and taking Jacques Derrida and Gilles Deleuze, we have centralized this research around Body and Experience's notion, highlighting the importance of such concepts as différance - to devise our own concept of Somatography and shed some light on the question of identity -, the Body without Organs - the production of an open body to all creative possibilities as well as the starting point to the actor/performer's work Becoming - expressive potencies, fleet lines to travel in the Body without Organs construction. On the other hand, thinking psychéphysys notion together with the exposed concepts, we propose a new understanding of the actor/performer Body/text relation opposed to the psychological construction of characters.

Keywords: Theatre/performance; Experience; Différance; Body without organs; Becoming.

\section{Introdução}

Os filósofos Jacques Derrida e Gilles Deleuze pouco terão em comum para o assunto que iremos aqui tratar. Onde um procurou, junto com Félix Guattari, as possibilidades do Corpo nas suas relações com o Mundo e os seus modos de se apresentar e funcionar (política, social, histórica e artisticamente, vd. em particular Mil Platôs: Capitalismo e Esquizofrenia vol. II), o outro pretendeu entender os modos do Corpo tocar noutros e a sua aproximação, no momento da fuga, ao Animal (por exemplo, Le Toucher e $O$ animal que logo sou).

Existe contudo, para nós, uma razão muito clara para questionar os dois filósofos. Na preparação de muitos espectáculos teatrais e performances em que participámos, temos tido a ocasião, no plano teórico, de convergir para a obra de Derrida e Deleuze, onde procuramos muitas vezes respostas para situações particulares e até mesmo questões que podem resultar em pesquisas práticas. 
Sendo o Corpo a nossa ferramenta por excelência, intentaremos neste breve artigo explorar alguns conceitos derrideanos e deleuzeanos de modo a explicitar a importância da experiência corporal (e não física, como mais adiante esclareceremos) do actor/performer ${ }^{1}$ no momento da sua investigação (ensaios, construção de uma partitura física e vocal, trabalho sobre o seu corpo e no encontro com o outro, etc.).

Parecerá, por vezes, que mesmo com toda a objectividade, no tratamento da questão a partir dos dois filósofos, sejamos subjectivos. É que os conceitos que tomamos de empréstimo e que analisamos procuram encontrar uma praticabilidade ainda não completamente entendida por nós (tanto na escrita como no nosso trabalho de actor/performer) e, esperamos, algum debate. $\mathrm{O}$ discurso sobre a experiência que aqui nos interessa, para além de ser sobre o corporal, é também estético, não se cingindo ao espectador mas mais ainda ao criador. É um discurso que procura ir ao encontro daquilo que Nietzsche aludiu no §VI no seu terceiro ensaio da Genealogia da moral, afirmando "que falta por completo a experiência pessoal:"

Kant julgou honrar a arte quando, entre os predicados da beleza, fez ressaltar os que constituem a honra do conhecimento: a impessoalidade e a universalidade. Não vou examinar aqui se isto foi um erro capital; quero apenas indicar que Kant, como todos os filósofos, em vez de estudar o problema estético baseando-se na experiência do artista, não meditou acerca da arte e da beleza senão como «espectador» no conceito beleza. (NIETZSCHE, 1997, p. 86-87, grifo do autor).

Tomamos a experiência como um Acontecimento, um aqui e agora vivido por um corpo, um instante que se escreve no corpo sem que nós tenhamos um conhecimento imediato. É um instante de recepção temporal e espacial de afecções e percepções sem mediação da consciência - pensamos, aliás, que não existe separação entre corpo e mente. A “tomada de consciência”, por ser tão rápida, pareceráimediata, mas encontra-se sujeita a uma diferenciação e a um diferimento (temporal e espacial), os quais potenciarão o entendimento e conhecimento da e sobre a experiência.

1 É necessário fazermos três ressalvas sobre este artigo. A primeira, trata-se de indicar a origem deste texto, devedora da investigação que nos propusemos e que resultou na nossa dissertação no Mestrado em Literatura e Poéticas Comparadas, Da Literatura, do Corpo e do Corpo na Literatura: Derrida, Deleuze e monstros do Renascimento. A segunda, partindo da primeira, implica o desvio da nossa investigação, isto é, pensar o Corpo no acto criativo teatral/ performático tendo em conta o que dissemos para o escritor e a escrita e a nossa prática profissional (enquanto alguém que escreve e exerce a profissão de actor/performer e encontra equivalências no que respeita ao corpo). A terceira e última é a clarificação da noção de actor/performer. Quando aqui falamos de actor/performer pensamo-lo sempre como um investigador e não como um mero intérprete e "funcionário" do dito teatro comercial, embora algumas das nossas conclusões poderão igualmente caracterizar esse tipo de actor. 
Cremos que é pensando sobre a(s) sua(s) experiência(s) que o actor/ performer constrói a sua imaginação, o jogo, que dá início a uma escrita do corpo em cena, à performance teatral, ao conhecimento do seu corpo. Contudo, também o fazer, o ver, a consciência do seu corpo, são experiências (experiências estéticas das quais não se pode ter uma postura desinteressada mas, ao invés, sempre interessada). Há por isso, pensamos, toda uma rede de experiências (assim como Derrida fala de uma rede metafórica, no seu texto Mitologia Branca) que não só se apresentam como singularidades - e que constantemente construirão a impossível de se abarcar, construir e definir na totalidade, identidade e presença de um corpo - como também estão sujeitas ao conceito de différance derrideano. Esta rede de experiências será aquilo que nomearemos mais adiante de Somatografia, isto é, uma escrita das experiências (singularidades diferenciadas e diferidas) num Corpo (entendido como physispsyché e como um Uno-Múltiplo) que potenciam e concebem novos mundos pelo actor/performer (como, por exemplo, as supostas personagens).

Por fim, gostaríamos de realçar que esta investigação, cruzando a filosofia e a teoria teatral e da performance, não tem ainda, em Portugal, a dinâmica e expressividade que se descobre noutros ocidentais.

\section{Da différance à somatografia}

O complexo conceito de Arquiescrita, como se sabe, articula-se com a différance e com a ideia de rasto, e encontramo-nos logo de sobreaviso que a arquiescrita não é um objecto, uma coisa, nem mesmo uma palavra (?). É a forma não-existente da escrita em geral. Mas se a arquiescrita não pode ser definida, se ela própria é escrita com o prefixo arché, que nos reenvia para uma anterioridade, uma origem, não se encontra ela no seio da metafísica, do logocentrismo? Sim e não. Afirmamos a sua pertença pela sua própria problemática, a sua impossibilidade de se "deixar reduzir à forma de presença", não o seu adiamento, porque ela é sempre o acontecimento da escrita e da fala, mas a sua aproximação do conceito inacessível de Idealidade. Mas pela sua interna articulação entre rasto e différance a arquiescrita é sempre lançada para fora do logocentrismo.

O rasto "descreve a estrutura implicada pelo «arbitrário do signo»" e "faz comunicar na mesma possibilidade e sem que possamos separálos a não ser por abstracção, a estrutura da relação com o outro, o movimento da temporalização e a linguagem como escrita" (DERRIDA, 2004, p. 57-58). 
O rasto é um devir, ${ }^{2}$ é o que permite "todas as oposições ulteriores entre physis e o seu outro" (DERRIDA, 2004, p. 58). Num encontro de signos, numa proximidade entre signos, e afirmamos desde já, também proximidade e encontro de corpos, cada um deles deixa uma marca no outro, originando tanto a identidade como a diferença entre signos (e entre significante/ significante, significado/significado) e corpos.

Esta marca, o rasto, possibilita o jogo das diferenças, a différance mesma ${ }^{3}$. Mas esta também não existe enquanto coisa. Não depende, é causa de dependência, é o acontecimento que articula o sensível e o inteligível, o interior dos signos e a relação destes numa estrutura (texto, fala e, acrescentamos, partitura física de uma dança ou performance). A arquiescrita (rasto + différance) possibilita a fala e a escrita, possibilita a relação do Eu e do Outro, do dentro e do fora, possibilita o espaçamento, a pausa, o silêncio, a relação entre espaços e tempos e a relação entre tempos, enquanto temporalização.

Mas onde é que "isto" se dá? Dá-se em todo o lado, no signo, no significante, no significado, na fala, na escrita, na leitura, sem se mostrar. Como se dá? Cremos que ela se dá como experiência, como soma de experiências, como suma de experiências, isto é, (n)o Corpo. No Corpo registram-se, marcamse, deixam-se os rastos, é a articulação, a possibilidade como também a impossibilidade no mesmo espaço, vida e morte, dentro e fora, espaço e tempo, etc. A arquiescrita nasce de uma escrita no e do Corpo, uma Somatografia e, simultaneamente, é o acontecimento desta.

Sabemos contudo, segundo Derrida, que a différance "não é, não existe, não é um ente-presente (on), qualquer que ele seja, e seremos levados a acentuar o que ela não é, isto é, tudo; e que, portanto, ela não tem nem existência nem essência. Não depende de nenhuma categoria do ente, seja ele presente ou ausente" (DERRIDA, 2004, p. 33). De modo nenhum o nosso salto, para o que indicámos há pouco como "somatografia", desfigura o que Derrida diz. Não afirmámos a sua dependência ao Corpo, indicámos um dos seus modos de se dar. O que apresentamos como hipótese parte de uma suposição admitida e permitida pelo próprio Derrida, quando ele (se) pergunta “o que é que difere? Quem difere?

2 DERRIDA, 2004, p. 58. "Sem remeter a uma «natureza», a imotivação do rasto sempre veioa-ser. Para dizer a verdade, não existe rasto imotivado: o rasto é indefinidamente o seu próprio vir-a-ser-imotivado." Sublinhado do autor. O devir, como veremos, é um conceito importantíssimo na filosofia deleuzo-guattariana, na relação com a infinita possibilidade de um corpo, de qualquer corpo.

DERRIDA, 2004, p. 77. "O rasto (puro) é a différance." Sublinhado do autor. 
O que é a différance?", avisando que ao mesmo tempo que atingimos "um outro lugar e um outro horizonte da problemática [...] cairíamos já aquém daquilo que acabamos de esclarecer" (DERRIDA, 2004, p. 46) acerca da différance.

Realizar estas perguntas seria como inserir uma diferença no conceito derrideano da différance - e não será isto, esta "traição", que Derrida realmente pede a todos os seus leitores? Para aceitar estas questões teremos de admitir os argumentos do filósofo franco-argelino, isto é:

[...] a différance é derivada, acidental, dominada e comandada a partir do lugar de um ente-presente, podendo este ser qualquer coisa, uma forma, um estado, um poder no mundo, aos quais seria possível atribuir qualquer espécie de nome, um quê, ou um ente-presente como sujeito, um quem. Neste último caso, particularmente, admitir-se-ia implicitamente que esse ente-presente, por exemplo, como ente-presente a si, como consciência, viria eventualmente a diferir: quer a retardar e a desviar-se da consumação de uma "necessidade" ou de um "desejo", quer a diferir de si. Mas, em qualquer destes casos, um tal ente-presente não seria "constituído" por essa différance. (DERRIDA, 2004, p. 47).

Ao mesmo tempo que nos permite, Derrida recusa-nos a localização da différance no Corpo por um impedimento desta se constituir num ente-presente. Todavia, o Corpo joga e não joga com a Metafísica (presença/ ausência, alma/corpo, etc.), está dentro e fora, é ele também um devir, uma temporalização e um espaçamento, é uma identidade de diferenças e repetições, é um rasto e produtor de rastos.

"«Um signo» escreve Umberto Eco em A theory of semiotics, «é tudo o que se pode considerar que substitui significativamente outra coisa. A semiótica é em princípio a disciplina que estuda tudo o que se pode usar para mentir. Se algo não se pode usar para mentir, tão pouco se poderá usar o inverso: para dizer a verdade." (CULLER, 1984, p. 103. Tradução nossa). Ora, um corpo é um signo dentro de uma certa estrutura ou contexto, mas ao mesmo tempo não é signo uma vez que nenhuma outra coisa o pode substituir significativamente (nós somos insubstituíveis e sabemos mentir tanto pela fala como pelo corpo). Contudo, ou pelo contrário, sendo um corpo um produtor de signos, ele próprio se pode produzir em signo por relações de força e poder, de intensidades, nos acontecimentos promotores das suas diferenças e, por conseguinte, sua identidade. Assim, como a língua é um sistema de signos que se diferenciam de outros, por uma questão de conexões - isto é, uma letra, por exemplo, por mais maneiras diversas que se possa escrever, apresentar-se pela escrita, "a sua identidade, como 
diz Culler, é puramente relacional" (CULLER, 1984, p. 93. Tradução nossa) um corpo, que não é uma língua, é igualmente um sistema de signos (órgãos, pele, pêlos, carne, etc.) que produz signos ou "quase-signos". ${ }^{4}$

Um corpo, dizíamos, é corpo por uma questão de relações, diferenças nascidas das conexões e analogias produzindo uma identidade sempre diferida e diferente. A nossa ressalva, e o nosso desvio, prendem-se ao facto de que num Corpo coabitam tanto as forças da consciência como as da "inconsciência", ${ }^{5}$ sem nenhuma predominância de uma sobre a outra, ao contrário do pensamento metafísico e de alguma fenomenologia. ${ }^{6}$

No próprio jogo destas duas forças, a consciência e a "inconsciência", age a différance como força, mas "a própria força nunca está presente: ela não é mais do que um jogo de diferenças e de quantidades. Não haveria força em geral sem a diferença entre as forças; e aqui a diferença de quantidade conta mais do que o conteúdo da quantidade, do que a grandeza em absoluta em si mesma" (DERRIDA, 1986, p. 50).

Um Corpo nunca é o mesmo, a sua identidade é sempre diferida em cada experiência e a somatização constante dessas experiências de diferentes forças e intensidades faz o Corpo. ${ }^{7}$ Mesmo a presença e ausência não são oposições no jogo da différance. No acontecimento da différance a nossa

4 Conceito que surge em GIL, 2001, p. 101.

5 Colocamos inconsciência entre aspas porque pensamos que tal não existe. Existem sim múltiplos estados de consciência, dos quais podemos estar mais atentos ou não da sua presença e regiões talvez ainda por desbravar e usar por falta de estudos e técnicas. Não acreditamos assim nos trabalhos sobre a inconsciência (no sentido psicanalista, isto é, pulsões oprimidas e bloqueadas, etc.) de alguns encenadores, profissionais e teóricos do teatro e da performance. Acreditamos, por outro lado, na produção de estados psicofísicos induzidos ou condicionados pelo trabalho sobre o corpo como, por exemplo, através do controlo da respiração. Mesmo certos estados emotivos suscitados pela memória podem ser repetidos (com diferenças que podem intensificar ou diminuir a intensidade da dita memória) somente através da respiração. $\mathrm{O}$ trazer à memória, presentificar uma qualquer lembrança e revivê-la é um processo, mais do que repetição, de produção. A memória não vem, é construída, isto é, produzem-se blocos de infância deleuzo-guattarianos, eles próprios a diferença na repetição.

6 DERRIDA, 1986, p. 49. "O privilégio atribuído à consciência significa pois o privilégio atribuído à presença; e mesmo se se descrever, à profundidade em que o faz Husserl, a temporalidade transcendental da consciência, é ao «presente vivo» que se atribui o poder de síntese e de reunião incessante dos rastos. / Este privilégio é o éter de uma metafísica, o elemento do nosso pensamento enquanto prisioneiro da língua da metafísica.

7 DERRIDA, 1996, p. 98. "Este movimento da différance não se verifica num sujeito transcendental. Produ-lo. A auto-afecção não é uma modalidade de experiência que caracteriza um ente que seria já ele próprio (autos). Produz o mesmo como relação a si na diferença consigo, o mesmo como o não-idêntico". Sublinhado do autor. 
identidade, enquanto presença frente a um outro, é sempre diferida/diferenciada pela identidade do outro (e vice-versa), é sempre marcada pela ausência do que foi presença antes do acontecimento. Assim como a identidade é sempre o somatório das diferenças passadas e futuras, a presença tem em si a marca da ausência do que foi e do que virá. Para ser presença, ela, deve passar por uma fase de devir-ausência, isto é, a presença só é presença porque ocupou o "lugar" da sua própria ausência no acontecimento (o que poderíamos chamar de uma somatografia no seu aparecer exterior, presença como escrita do corpo no espaço), presença por ocupação ou arrombamento do que era ausência.

\section{A máquina desejante homem}

Quando Deleuze e Guattari nos expõem o Mundo como sendo um enorme território, o Corpo Pleno da Terra, povoado de máquinas, não estão a usar metáforas. Disso nos põem logo de sobreaviso desde o início da sua aventura filosófica a meias: "O que há por toda a parte são mas é máquinas, e sem qualquer metáfora: máquinas de máquinas, com as suas ligações e conexões. Uma máquina-órgão está ligada a uma máquina-origem: uma emite o fluxo que a outra corta" (DELEUZE; GUATTARI, 2004, p. 7). Esta afirmação dá um certo cariz holístico à relação do Homem com tudo o que o rodeia, o que o faz ser o que é, o que produz, o que recebe; faz com que tudo se comunique (comunicação não no sentido linguístico do termo, uma vez que, para Deleuze e Guattari não há informação mas direcção, ordenação). Comunicação como passagem, como ligação, conexão entre partes, não havendo lugar a independências, a mecanismos solitários. Sendo tudo máquinas, o que os dois autores pretendem avaliar é a sua produção e o seu funcionamento maquínico.

De facto, o que apenas existe é produção e produção de três tipos: produção de produções, produção de registos e produção de consumos. A primeira produção trata as acções e reacções, a segunda a distribuição e referências, a terceira os afectos e perceptos. Seguimos a par e passo a lei de Lavoisier, "na Natureza nada se perde tudo se transforma". Por outro lado, Deleuze e Guattari promovem uma noção alterada da realidade do Homem e da Natureza, bem como do homem/homem e de si a si. Já não existe separação de essência entre homem e natureza, pois ambos são produtores, o homem deixa de ser um criador para passar a ser a máquina que põe a funcionar todas as outras máquinas ("o eterno encarregado das máquinas do universo") (DELEUZE; GUATTARI, 2004, p. 10). 
A primeira instância das máquinas, de todas as máquinas, é serem máquinas desejantes de sistema binário linear, isto é, uma máquina liga a outra, uma produz um fluxo "e depois" a outra extrai ou corta para si esse mesmo fluxo. Como o nome indica, o que há é produção de desejo e o desejo "faz constantemente a ligação de fluxos contínuos e de objectos parciais essencialmente fragmentários e fragmentados. O desejo faz correr, corre e corta" (DELEUZE; GUATTARI, 2004, p. 11). É necessário entender estes objectos parciais como tudo, tanto uma pedra como um rim, de onde se podem destacar outros "objectos parciais" que são os fluxos desses objectos e destes ainda outros e outros "e... e":

Qualquer «objecto» supõe a continuidade de um fluxo, e qualquer fluxo a fragmentação de um objecto. Não há dúvida que cada máquina-órgão interpreta o mundo inteiro a partir do seu próprio fluxo, a partir da energia que dela flui: o olho interpreta o tudo em termos de ver [...] Mas há sempre conexão que se estabelece com outra máquina, numa transversal onde a primeira corta o fluxo da outra ou «vê» o seu fluxo cortado. (DELEUZE; GUATTARI, 2004, p. 11).

Como e onde se situa o Homem entre as máquinas? É não só o encarregado, mas também máquina desejante. Não está no centro da produção, que é a própria máquina social técnica, mas na margem da máquina atravessado pelos fluxos. Daí a sua impossibilidade de adquirir uma identidade fixa, porque ele está sempre a ser atravessado e alterado, passando por diferentes estados, sempre e sempre. Cada máquina, e no homem cada máquina-órgão, contém um determinado código ${ }^{8}$ que se transcreve em cada fluxo. Esse código insere-se não só na produção mas igualmente no registo, logo, na ligação entre máquinas há assim uma descodificação (tradução) de códigos noutros, podendo cada código ainda adquirir outro código no seu seio 9 (podemos imaginar, por exemplo, um grande código, o DNA humano como grande código do Homem, onde se encontram já pedaços de diferentes códigos, códigos de órgãos, de membros, etc.).

A máquina, como já vimos, realiza três tipos diferentes de produção (o produto é o desejo) e a máquina desejante, como primeiro estádio da máquina, tem como tarefa o corte de fluxos, ou produtos, e ser cortada igualmente de três

8 DELEUZE; GUATTARI, 2004, p. 42. "O código parece-se menos com uma linguagem do que com uma gíria, formação aberta e plurívoca".

9 DELEUZE; GUATTARI, 2004, p. 41. "Um órgão pode estar associado a vários fluxos segundo conexões diferentes; pode hesitar entre vários regimes, e até apropriar-se do regime de um outro código (a boca anoréxica [sic])." 
maneiras, de modo a destacarem partes da libido para a produção de desejo, de acordo com os três tipos de produção: o primeiro corte remete para uma síntese conectiva, mobilização da libido para a extracção de códigos; o segundo para uma síntese disjuntiva que permite a libido destacar e registar o código (o que os autores chamam o Numen); o terceiro remete para uma síntese conjuntiva, que é a libido como energia de consumo (a Voluptas).

Desta maneira são apresentadas as operações do desejo: um indivíduo acha-se num determinado local e tempo (a realidade desse ponto); dá-se um acontecimento que ele presencia; o indivíduo experiencia esse acontecimento, que já se encontra inserido numa máquina social técnica (um corpo pleno ${ }^{10} \mathrm{e}$ aqui entra a máquina desejante a funcionar; do evento extrai o código do fluxo de desejo na ligação entre o indivíduo e o acontecimento, a seguir destaca e regista no seu corpo e depois enquanto consome essa energia produz desejo que poderá ser canalizado para outros produtos (como a arte). O que é que o desejo produz? Real:

O desejo é esse conjunto de sínteses passivas que maquinam os objectos parciais, os fluxos e os corpos, e que funcionam como unidades de produção. O real resulta disso, é o resultado das sínteses passivas do desejo como autoprodução do inconsciente. Ao desejo não falta nada, não lhe falta o seu objecto. É antes o sujeito que falta ao desejo, ou o desejo que não tem sujeito fixo; é sempre a repressão que cria o sujeito fixo. O desejo e o seu objecto são uma só e mesma coisa: a máquina, enquanto máquina de máquina. O desejo é máquina, o objecto de desejo é também máquina conectada, de modo que o produto é extraído do produzir, e qualquer coisa no produto se afasta do produzir, que vai dar ao sujeito nómada e vagabundo um resto. O ser objectivo do desejo é o Real em si mesmo. (DELEUZE; GUATTARI, 2004, p. 31).

Todo o homem habita uma máquina social técnica (um país e o seu Estado, uma religião, uma cultura, uma justiça, uma língua, etc.), isto é, um corpo pleno (molar) que condiciona um conjunto de modos de vivências e práticas aos vários indivíduos (moleculares). ${ }^{11}$ Por outro lado, todo o homem também habita as

10 A Terra é o grande corpo pleno, a grande desterritorializada, sempre a criar linhas de fuga, fluxos de desejo a serem povoados por outros corpos plenos: "A máquina é, em primeiro lugar, uma máquina social constituída por um corpo pleno como instância maquinizante, e pelos homens e utensílios que são maquinizados na medida em que estão distribuídos sobre esse corpo". DELEUZE; GUATTARI, 2004, p. 419.

11 Molar e Molecular são termos relacionados com os devires do homem (que iremos analisar mais adiante) que indicam estados das passagens psicofísicas do corpo que podem condicionar uma escrita, por exemplo. Mas correspondem igualmente ao modo de organização dos corpos num determinado regime, isto é, o estado molar corresponde ao grande aglomerado de moléculas, que podem fugir ou saltar para outros regimes, e cada molécula pode potenciar um outro regime molar. 
máquinas desejantes. De acordo com os autores ele povoa as duas não por serem diferentes máquinas, mas por serem a mesma máquina. O que diferencia as duas não está no seu produto, está antes no regime que as maquina, que as põe a funcionar.

A máquina social língua cria um território, ou reterritorializa, codificando o desejo segundo uma ordem, um parâmetro, certas regras, enquanto a máquina desejante homem funciona no sentido da desterritorialização, desejo como linha de fuga, desejo para avariar e como avaria da máquina social. ${ }^{12}$ Os autores chamam-nos a atenção para a produção de registo, o que nos lembra e vai ao encontro daquilo que procuramos neste artigo e de como entendemos arriscadamente todo o processo da différance. O registo pode ser uma escrita, se entendermos escrita como uma cadeia de signos com múltiplos sentidos (plurívoca) e inscrita numa linha temporal (transcursiva). "É uma escrita com a forma do Real" (DELEUZE; GUATTARI, 2004, p. 42) que organiza os signos descodificados dos desejos produzidos nas sínteses passivas, organização de signos que não se referem a nenhum significante e que, depois de terem sido codificados, nunca virão a ter ou a ser significante, apenas e somente desejo. ${ }^{13}$ O homem ao pôr a funcionar e avariar a máquina desejante para ser máquina desejante artística, ${ }^{14}$ constrói, ou necessita de construir, aquilo que só podemos ver como abstracção (o sonho de Artaud), isto é, um Corpo sem Órgãos (CsO), aquilo que os autores indicam como a anti-produção dentro da produção.

\section{Corpo sem órgãos e a sua construção}

CsO não é um corpo como organismo de órgãos organizados, que compreende tanto as ligações como as falhas entre os órgãos, os bloqueios, os hiatos, mas um cilindro percorrido por um único fluxo amorfo (múltiplos fluxos num só), sem separações de corpo e mente/espírito, ${ }^{15}$ é o espaço virtual do nosso

12 DELEUZE; GUATTARI, 2004, p. 35. "A arte utiliza muitas vezes esta propriedade ao criar verdadeiros fantasmas de grupo que curto-circuitam a produção social com uma produção desejante, e introduzem uma função de avaria na reprodução de máquinas técnicas."

13 DELEUZE; GUATTARI, 2004, p. 43. "A única vocação do signo é produzir desejo, e em todos os sentidos."

14 DELEUZE; GUATTARI, 2004, p. 35. “[...] a própria obra de arte é uma máquina desejante. O artista acumula o seu tesouro para uma explosão próxima, e é por isso que se impacienta com o tempo que falta para que as destruições se venham a dar". Tal como a célebre frase de Mikhail Bakunin: "A volúpia de destruir é, ao mesmo tempo, uma volúpia criadora."

15 NANCY, 2000, p. 36. “[...] não há sentido em falar separadamente do corpo e de pensamento, como se cada um pudesse subsistir por si: é que eles são apenas o seu mútuo tocar-se, o toque da efracção de um pelo outro e de um ao outro. Este toque é o limite, o espaçamento da existência". Sublinhado do autor. 
próprio corpo. CsO como lugar da physis-psyché, sem ligação a um Significante, a uma Metafísica, corpo produtor de intensidades a partir do grau zero de intensidade, corpo de pura sensação e nunca de representação, corpo de desejo.

O CsO é assim o momento em que a criação se dá, um alheamento da identidade (que, como já vimos, é mutável) e máxima concentração no desejo, absoluta produção de desejo para produzir outra máquina desejante (a obra de arte, a arte, mas também existem CsOs políticos, científicos, místicos, perversos, etc.). ${ }^{16} \mathrm{Na}$ construção de um $\mathrm{CsO}$ a criação é um delírio e uma viagem.

O que os autores referem relativamente à criação literária, na qual se dá um delírio da língua, procura de potências gramaticais e sintácticas, de um estilo, tensores, uma língua menor; e no seu próprio lugar, sem o escritor sair sequer de si, uma viagem pelos espaços intensivos do corpo, descoberta de territórios, tribos, povos, culturas, nações e religiões exactamente onde ficaram os afectos e perceptos inscritos como intensidades, ${ }^{17}$ é o que pensamos que existe, se pede e se dá no corpo do actor/performer. Quando em processo de investigação, e mais ainda durante o processo de aquecimento corporal, o que se procura é todo um alheamento ou separação de si-próprio, isto é, o que o "define" como indivíduo único e pessoal, exactamente aquilo que obstrui a livre passagem de energia e que organiza o $\mathrm{CsO}$ e o transforma em organismo. Ao actor/performer é-lhe pedido que procure e construa a sua própria linha de fuga e que a percorra. A personagem que representará não é o conjunto de palavras de um texto, ou a incarnação de um espírito qualquer, mas a própria adequação de duas escritas que se entrelaçam.

De um lado temos a partitura física concretizada pelo corpo e voz, onde se incluem igualmente as respirações, emoções, movimentos, etc. Poderíamos dizer que esta partitura física se apresenta de um modo extensivo, isto é, produção de linhas e seu deslocamento espacial em todas as dimensões, e de um modo intensivo, produção e deslocamento afectivo. O trabalho sobre esta partitura implica uma total liberdade, dá sempre lugar ao acaso e à improvisação. Do outro lado encontramos o texto que será dito, corpo estranho, prótese linguística que o actor/performer terá de dominar, fazê-lo seu (a veracidade que o espectador afirma existir quando vê realmente ali um Hamlet em vez deste ou aqueloutro actor), enquanto é ao mesmo tempo

16 DELEUZE; GUATTARI, 1997, vol. III, p. 15. "O CsO é o campo de imanência do desejo, o plano de consistência própria do desejo (ali onde o desejo se define como processo de produção, sem referência a qualquer instância exterior falta que viria torná-lo oco, o prazer que viria preenchê-lo)". Sublinhado dos autores.

17 DELEUZE, 2002, p. 10. "Toda a obra [como a literária] é uma viagem, um trajecto, mas que apenas percorre este ou aquele caminho exterior em virtude dos caminhos e trajectórias interiores que a compõem, que constituem a sua paisagem ou o seu concerto." 
dominado. Queremos dizer, o actor não pode fugir ao texto, tem a obrigação de o apresentar com o mesmo número de palavras com que lhe foi dado pelo autor (falamos em termos genéricos, claro, já que o encenador pode decidir o modo como quer utilizar um texto). Comparativamente com a partitura física, a outra escrita que se entrelaça ao texto, este impõe-se como um bloco demasiado rígido, escapando-se a ele apenas através do erro (a "branca", a dislexia, a gaguez involuntária, etc.).

Aquilo que se vê, quando as duas escritas se encontram, isto é, a sobreposição de um corpo (actor/performer) sobre outro (o corpo invisível do texto), é um novo corpo. Uma projecção de um corpo fantasmático (implicando o seu conceito familiar, o fenómeno), um corpo virtual daquele acontecimento que já não é nem a personagem textual nem o actor/performer X nascido no ano e no dia tal, etc. Isto também sucede porque simultaneamente é despertado o acordo entre o olhar proposto e o daquele que vê, queremos dizer, o público deseja ver esses corpos virtuais. Se não os vê é porque a máquina não funciona e essa é já outra questão.

\section{A importância dos devires na construção do CsO}

Os devires não são representações, nem imitações, nem metáforas, nem sequer uma exterioridade visível e apontada num texto ou a subjectividade do autor, de um músico, de um encenador, de um actor/performer. Os devires qualquer coisa ${ }^{18}$ são as linhas de fuga que partem do CsO no acto criativo. São estados intensivos das sensações (afecções e percepções, o que indicaremos como o que "ganhamos" das experiências, o que fica em nós das experiências) inscritas, marcadas, registadas no corpo. $\mathrm{O}$ delírio e a viagem de que falámos são reais e primeiramente físicas. O fluxo amorfo que nos percorre, no momento do nosso $\mathrm{CsO}$, destaca dos objectos parciais as marcas das experiências transformando-as em blocos de sensações de afectos e perceptos que serão depostos no texto, pela escrita, ${ }^{19} \mathrm{e}$ na cena, pelo corpo. É um processo psicofísico, é a dificuldade e depois o correr desenfreado da escrita, são as dificuldades,

18 Deleuze e Guattari definem pelo menos cinco devires essenciais, que o homem desencadeia no seu corpo, e que podem ou não estar conectados encontrando o limite no último que indicaremos aqui nesta nota: devir-mulher, devir-minoritário, devir-revolucionário, deviranimal e devir-imperceptível.

19 DELEUZE; GUATTARI, 1992, p. 149. Os afectos são precisamente esses devires não humanos do homem, como os perceptos (incluindo a cidade) são as paisagens não humanas da natureza. (grifo do autor). 
bloqueios e limites do corpo que depois fluem nos movimentos e gestos, é o Corpo a funcionar para que haja Literatura, para que haja Teatro e Performance, ou segundo os autores, uma fenomenologia da arte:

O ser da sensação, o bloco do percepto e do afecto, surgirá como a unidade ou a reversibilidade entre aquele que sente e o sentido, o seu íntimo entrelaçamento, à semelhança das mãos que se apertam: é a carne que se vai separar simultaneamente do corpo vivido, do mundo percebido, e da intencionalidade de um a outro ainda demasiado ligada à experiência - enquanto a carne nos dá o ser da sensação, e traz a opinião originária distinta do juízo de experiência. (DELEUZE; GUATTARI, 1992, p. 157, grifo do autor).

À pergunta de Espinosa que Deleuze recorrentemente cita, o que pode um corpo?, respondemos quase de rompante que ele pode tudo, embora saibamos que o conhecimento do que realmente pode um corpo terá de ser produzido infinitamente na conjugação de várias disciplinas científicas e nunca alcançado, porque uma vez "tocado" perde-se o corpo pela différance e pela própria finitude de um corpo, o seu fim desde origem inscrito no corpo, a sua morte.

$\mathrm{O}$ que nos parece um paradoxo, uma vez que temos à mão um objecto finito, como que fechado, limitado pelo seu fim, mas nunca apercebido porque qualquer um se perde, se desorienta na sua geografia, nas suas paisagens, nos abismos. Como no aforismo de Nietzsche, que citamos de memória, que nos diz que quando olhamos para o abismo ele olha para nós, quando olhamos para um corpo recebemos de volta um corpo, possuímos um corpo, vemos um corpo $^{20}$ e por esse motivo se pergunta o que é um corpo?

Um corpo é um complexo de relações de forças (no sentido nietzscheano), de fluxos de energia ou desejo (no sentido deleuzo-guattariano), o jogo da différance (no sentido derrideano). É um erro conceber um corpo ainda na concepção platónica e religiosa, como dualidade de matéria e espírito, e não como physis-psyché composto sempre pela mesma energia embora com funcionamentos diferentes, com produções diferentes em relações diferentes. ${ }^{21}$

${ }^{20}$ DELEUZE; GUATTARI, 2004, p. 14-15. "Possuir, é dar a possuir e ver isso que é dado, vêlo multiplicar-se na dádiva. [...] O eu é "dissoluto" porque, primeiramente, ele é dissolvido: não apenas o eu que é olhado e que perde a sua identidade sob o olhar, mas também quem olha e desse modo se coloca fora de si e se multiplica ao olhar."

21 DELEUZE, 2001, p. 62. "O que define um corpo é esta relação entre forças dominantes e forças dominadas. Qualquer relação de forças constitui um corpo: químico, biológico, social, político. Duas forças quaisquer, sendo desiguais, constituem um corpo a partir do momento em que entrem em relação: é por isso que o corpo é sempre fruto do acaso." 
O corpo é esse Uno-Múltiplo, conjunto de quantidades de força com diferentes qualidades (aquilo que, no entender de Nietzsche, surge como activo ou reactivo) em relação com outras quantidades e qualidades de força. Um corpo faz-se pela relação e exprime-se em relação a outros corpos, tocar e ser tocado, ver e ser visto, sentir e dar a sentir, afectar e afectar-se. Contudo isto não diz o que é um corpo, a dificuldade de se falar do corpo existe porque ele resiste à linguagem, isto é, tudo o que ele implica no desenrolar da sua história, nas suas potências e possibilidades esquiva-se à linguagem, à língua.

Essa é aliás a maior dificuldade apontada pelos filósofos José $\mathrm{Gil}^{22}$ e Jean-Luc Nancy. ${ }^{23}$ A própria dificuldade reside igualmente no facto de que o corpo por si só é apenas expressão, não significa nada se não se articular com os códigos das linguagens para se poder comunicar. Essa contrariedade exprime-se, por exemplo, na quase total impossibilidade de se criar uma língua específica do corpo nas artes ditas corporais (teatro, dança, performances, etc.), de reduzir os gestos a signos como os de uma língua fonética, "gestemas" como fonemas ou monemas. ${ }^{24}$

A expressão de um corpo não se destaca na sua parcialidade (só uma mão, o rodar de uma cabeça) mas toda a conjugação das partes numa unidade espaço-tempo. No entanto, no dia-a-dia, existe uma concordância ou uma aproximação estreitíssima entre a fala e os gestos, uma clareza significativa, comunicativa, aquilo que Gil entende como uma disciplina do corpo. Trata-se de um contínuo apagamento da expressividade em virtude do código da língua mais comunicativo (ou de ordenação), e isso é entendido à luz do estudo de Michel Foucault, Vigiar e Punir, onde o corpo do indivíduo é encerrado em certos cenários educativos (escola, exército, hospital, prisão e a própria família):

\footnotetext{
${ }^{22}$ GIL, 1997, p. 13. "Qualquer discurso sobre o corpo parece ter que enfrentar uma resistência. [...] cada definição permanece um ponto de vista parcial, determinado por um domínio epistemológico ou cultural particular." Chamamos a presença deste fascinante filósofo por variadas razões. A menor, mas sem menos importância, será a sua filiação deleuziana. Por outro lado, é necessário e pertinente relevar o valor dos seus contínuos estudos e contributos sobre o Corpo, os Monstros, a Literatura, para além de, ao que nos for permitido aqui, humildemente reconhecer a sua mais-valia para a cultura portuguesa e o presente estudo.

${ }^{23}$ NANCY, 2000, p. 7. "E todas as teorias do «corpo próprio», as laboriosas tentativas para reapropriar aquilo que se julgava deploravelmente «objectivado», ou «reificado», todas essas teorias são contorções análogas: apenas acabam por expulsar aquilo que se desejava."

${ }^{24}$ GIL, 2001, p. 88. "Não há «gestemas» discretos, comparáveis aos monemas nem unidades insecáveis não significativas, como os fonemas. De onde a inexistência de uma «dupla articulação» de uma linguagem do corpo, à maneira da da linguagem falada."
} 
Melhor: sob o apagamento da tendência para a singularidade da quasearticulação [a expressividade] do corpo, desponta por vezes aquilo que lhe subjaz, o fantasma do corpo informe, do monstro, do corpo louco, selvagem; o fantasma do visceral, do corpo sujo ou do corpo mortífero epidémico. Esses fantasmas constituem o pano-de-fundo inominável que é necessário controlar ou eliminar, se se quiser ter corpos funcionais. (GIL, 2001, p. 93).

Uma das possibilidades do corpo é, segundo Gil, a produção de quase-signos, isto é, embora sendo signos não-significantes, e por isso o prefixo quase, são, no entanto, portadores de sentido. São unidades que traduzidas no código da língua podem vir a ser signos, porque "os órgãos sensoriais, o corpo e as suas funções tecem sentidos com o mundo que só eles estão em condições de compreender imediatamente e sem "reenvio". Qual é o sentido do vermelho? Esgota-se na sua percepção, de imediato e totalmente - e esse sentido revela-se inesgotável pela linguagem. Do mesmo modo, há movimentos corporais que contêm em si a sua significação completa" (GIL, 2001, p. 105). Por essa razão podemos entender a leitura de um texto não como um processo puramente mental, mas igualmente, senão primeiramente, físico, um processo de aproximação das palavras escritas às percepções e afecções marcadas no Corpo, um processo de encaixe do sentido fonético ao sentido psicofísico. É o que, de outro modo, o filósofo português indica como uma infralíngua, isto é, toda essa adequação da articulação da linguagem falada à articulação do corpo, e mais além, o que está escrito (ex-crito) com o que está inscrito (in-scrito).

A infralíngua é o que permite que um corpo execute as passagens de códigos a outros sem reenvios a sentidos transcendentais, muito para lá do humano. A infralíngua é, segundo Gil, um processo de incorporação da linguagem falada, no sentido do que indicámos com as argumentações à volta da différance, uma inscrição das sensações ou do sentido das palavras, sujeitas a uma gramática e sintaxe simplificadas. Embora o filósofo português explane a infralíngua relativamente ao ritual de cura xamânico e momos, acreditamos que esta plasticidade ou inteligência corporal do mundo não se perdeu, é, aliás, bastante presente na maior parte dos processos e actividades artísticas (como confirmam muitos estudos de antropologia da arte). ${ }^{25}$

25 Por exemplo Barba e Savarese, 2004. 
A infralíngua forma-se ao mesmo tempo que a linguagem verbal, tem o mesmo tempo. Uma e outra são síncronas no instante de qualquer aprendizagem e a infralíngua arrasta-se, cola-se à linguagem verbal. Talvez possamos dizer que a escrita tem uma infralíngua que se manifesta a par com o acto escrito, os contínuos movimentos e gestos mínimos que se desencadeiam no nosso corpo, cruzares e descruzares de pernas, coçares, esgares, caretas incompreendidas, imperceptíveis, certas deslocações bruscas que correspondem a outros no pensamento. Isso acontece porque não existe o não-movimento, existem sempre ínfimos esforços, forças que se manifestam no espaço interior do corpo que, por exemplo, concretizam o equilíbrio constante e banal. Mas também porque a infralíngua "oferece ao pensamento e à linguagem mais que uma matriz (por exemplo, de oposições lógico-empíricas, esquerda/direita, interior/exterior), um procedimento geral para pensar o mundo, quer dizer, para que o mundo sensível, variável, caótico, adquira ordem e sentido" (GIL, 1997, p. 47).

Ora, o que sucede, no acto performático, é que a consciência se torna consciência do corpo. Pensamento e corpo são um só, physis-psyché, e qualquer movimento físico é igualmente movimento mental, do pensamento. Quando observamos alguém a sentar-se e também nos encontramos sentados, o nosso pensamento senta-se connosco e com aquele(a) que agiu, ou, de outro modo, quando lemos, por exemplo, o mergulho de Moby Dick, o nosso pensamento mergulha com a baleia branca, à semelhança dos traços dinâmicos apontados por Deleuze e Guattari (1992). O corpo presentifica-se no pensamento. ${ }^{26}$

A par da infralíngua, Gil, a partir de Lévi-Strauss, indica a presença de um significante flutuante como aquilo que possibilita o pensamento simbólico, não apenas presente nas sociedades primitivas mas igualmente no fazer artístico. O significado flutuante "designa sempre uma energia, uma força que é impossível ver significadas em códigos, visto que estes falam das coisas e das suas relações e não do que as torna possíveis" (GIL, 1997, p. 19). O significante flutuante é assim como uma superabundância de significância, um excesso de sentido das coisas. Se o corpo é percorrido por energia, o significante flutuante é o que permite o transbordamento de vida, do imprevisível, múltiplo

26 Apresentamos um exemplo de uma actriz de Nô e de Kabuki que, de certa maneira, alude a esta presentificação do corpo no pensamento: “[ [...] em certos espectáculos, quando somente um dos actores está dançando e os outros viram as costas ao público e se sentam em frente aos músicos, os actores que se encontram desse modo costumam relaxar. «Eu não relaxo diz Matsumoto Nazaemon - «mas sigo toda a dança na minha mente. Se não o fizesse, a visão das minhas costas seria tão desinteressante que molestaria o olhar do espectador»." BARBA, 1994, p. 50. 
e espontâneo da vida. Contudo, devido a uma ordenação social do mundo, do estabelecimento de regras em todos os campos, o significante flutuante não desponta no seu máximo fulgor. Ele surge ainda por toda a (p)arte mas sujeito a uma "economia de poderes singulares e dos signos colectivos, cujo fim é, mais uma vez, o de permitir ao corpo desempenhar o seu papel de suporte de códigos e de acumulador de energia" (GIL, 1997, p. 48).

\section{Corpo, atmosfera e devir}

De acordo com Gil, o corpo percepcionado, a sua exterioridade, é coberto de traços da subjectividade do indivíduo (todas as suas emoções, sensações, afectos, percepções), é uma tradução expressiva realizada por gestos, movimentos, sons, tiques, mímicas. Se o interior é um espaço de inscrição, que passa para o exterior, é preciso ver que o próprio exterior é também espaço de inscrição. O espaço interior é o papel poroso que permite comunicar a psyché com a physis, é o que permite falar de um "espaço psíquico", talvez outro muro branco-buraco negro (DELEUZE; GUATTARI, 1997, p. 31-61) onde se escrevem as significâncias e subjectivações do que se diz ser o inconsciente. Mas todo o espaço exterior é envolvido por um ciclorama imenso de duas faces que é a pele, fronteira entre o interior e o exterior, condicionante principal para a realização do corpo como physispsyché. É o que o filósofo português chama de espaço-charneira, uma vez que a pele, enquanto fronteira de um espaço exterior e de um interior, é igualmente passagem comunicativa.

A comunicação faz-se acima de tudo por um acordo e contaminação de ritmos afectivos entre duas pessoas, por concordâncias (choques e filtragem de significâncias e subjectivações), por esboçar o corpo do outro no nosso, o que pode despertar um devir-outro. Portanto, pele e psyché, em contínua comunicação, produzem o Corpo de que temos vindo a falar. Mas este é também um corpo que nunca é nosso senão num limite que jamais teremos consciência, uma vez que cada experiência, cada acontecimento, cada comunicação, etc., se escreve como marca do outro. A nossa identidade é diferenciada/diferida pelos rastos do(s) outro(s), o nosso espaço interno é de outros, povoado pelos outros. Não há qualquer objectividade na construção do nosso corpo já que ele se compõe através das nossas percepções, o que significa que toda a percepção do corpo do outro é subjectiva. 
Quando percepcionamos realizamos um agenciamento de sensações e forças e, exactamente por essa razão, não nos é possível separarmos do objecto observado, somos atravessados pelos olhos, pela pele, pelo nariz por milhares de determinantes subjectivas, somos iluminados pelos halos das pequenas percepções:

Há sempre um halo de pequenas percepções que [...] imprimem [aos objectos] infinitos movimentos imperceptíveis, dando-lhes mais ou menos força atractiva, pregnância, brilho. Assim se explica que o amor transforma a percepção do corpo amado: não há invariante objectivo percepcionado, mas sim um turbilhão de movimentos microscópicos que envolve e arrasta as formas. Por isso, a percepção do corpo humano tem sempre uma carga afectiva: percepcionar é transferir, entrar em relação de transferência. (GIL, 1997, p. 182-183).

Nós não temos, no dia-a-dia, consciência do que é o nosso corpo, a nossa consciência é uma inconsciência do corpo. O momento consciente de physis-psyché surge com a produção de um $\mathrm{CsO}$, o qual também não temos consciência pela sua própria virtualidade, mas, pleno de desejo, cheio de um "poder transformador e [de] devir - devir sensitivo, afectivo que atinge e desorganiza a unidade da consciência" (GIL, 1997, p. 185). Quando se trabalha nos objectos, eles não são já à partida artísticos, o criador não pensa que está a produzir um objecto artístico, estético. A sua consciência está centrada no objecto em si (está interessado no objecto), na produção e inscrição do seu desejo no objecto, e na abertura de si ao exterior, a toda a atmosfera, a todas as pequenas percepções que o rodeiam ${ }^{27}$ - é o estado que muitos encenadores e actores/ performers chamam de escuta, quando em ensaios ou em cena. ${ }^{28}$

O Homem faz $\mathrm{CsO}$ com a atmosfera-arte para criar, produzir objectos artísticos. Uma só máquina com duas componentes virtuais, que apenas surgem, se produzem, se houver uma certa concentração: concentração em si, concentração no objecto, concentração na atmosfera. Queremos dizer que, concentração tanto significa estarmos atentos ao nosso corpo, ao que se está a produzir no interior, isto é, centrarmo-nos em nós; mas também, estarmos

27 GIL, 1987, p. 164. "O fim da arte não é exterior à arte; por conseguinte o escritor não escreve para fazer arte, mas para completar um processo de exteriorização do interior, que iniciou com a análise das sensações."

28 OIDA, 1997, p. 105. [...] on a trois niveaux d'activité et de conscience: la présence physique dans l'espace, la relation aux autres et cet observateur silencieux." 
despertos a receber o que vem de fora para reencaminhar as sensações, afecções e percepções, para o que se está a produzir, isto é, (con)centrarmo-nos em relação $a$. Esta concentração é uma abertura, é uma consciência inconscientemente consciente, despreocupada, é physis-psyché, é CsO que se maquina com uma atmosfera-arte. Queremos dizer que, entre, ao lado, por cima, por baixo, à volta, em todas as direcções e sentidos que se encontram na relação actor/performer e os outros, a produção de desejo produz um corpo virtual, que é o CsO, e um "meio", que possibilita o contacto à distância. ${ }^{29}$

A atmosfera, no sentido que agora apresentamos, é um conceito de Gil relacionado com o corpo na dança, mas pensamos que este mesmo conceito se pode estender a outras áreas artísticas. Uma atmosfera é um meio de contacto entre corpos, envolvendo-os e estabelecendo relações de força, mas a sua própria força vai para além de se manter como meio. Para o filósofo, a atmosfera é a:

Invasão da consciência pelo inconsciente; no mesmo acto, é o espaço do corpo - esse prolongamento do corpo no espaço - que se impregna de forças inconscientes. A atmosfera não se limita portanto à consciência, habita o exterior dos corpos [...]. Os corpos exalam um espaço (o espaço do corpo) e todo o contexto dos objectos se acha assim modificado, carregando-se o espaço objectivo de forças, de lugares magnéticos, de territórios proibidos, de atracção ou de ameaça. Então a atmosfera surge desligada dos corpos, existindo de modo autónomo e envolvente; dizemos: «está no ar». A atmosfera está no ar. (GIL, 2001, p. 147. grifo do autor).

A atmosfera é constituída pelas pequenas percepções que serão capturadas pelo corpo e despertadas, recolhidas, traduzidas a partir, ou no momento, do $\mathrm{CsO}$; mas também apresenta, segundo o filósofo, uma "densidade", "textura" e "viscosidade" variáveis. Uma atmosfera pode ser um conjunto de várias atmosferas com arranjos diferentes destas três componentes, o que pode explicar as ocasiões de maior fluidez e/ou maior dificuldade no traçamento e decorrer de um objecto artístico. A diferença encontra-se, pensamos nós, no que respeita a produção e encontros de desejos, na imediaticidade. No bailarino, no actor, no performer e até no músico, a sua relação com o desejo situa-se no imediatismo, nas presenças e ausências "presentes" e imediatas, porque o desejo trata o acontecimento, o aqui-agora;

29 Existe no Japão uma expressão que revela a capacidade deste tocar de longe, usada pelos espectadores para agradecer o trabalho dos actores: otsukarasama, isto é, "você cansou por mim”. BARBA, 1994, p. 31. 
enquanto num escritor, num artista plástico e também num músico, a relação é mediata, diferida, atrasada, pela presença/ausência tanto do autor como do leitor/ouvinte, mas o contacto com o outro não deixa de existir.

Aquilo que um criador, e neste caso actor/performer, dá, aquilo que é comunicado, que entra em contacto, para além de desejo produtor, é, segundo Deleuze e Guattari, blocos de sensações compostos de afectos e perceptos. Os afectos e os perceptos, não só se marcam vindo dos outros, mas igualmente da atmosfera, isto é, o conjunto das pequenas percepções.

A arte, apresentando-se como atmosfera, é o que permite ao criador arrancar às percepções e afecções os perceptos e afectos, é o que permite ao criador fazer passar o seu material particular pelas sensações e produzir um bloco. No nosso caso, sobre aquilo que tratamos, o actor/performer, com o seu $\mathrm{CsO}$ e envolvido por uma atmosfera, faz passar as palavras pelas percepções e afecções para trazer ao de cima perceptos e afectos. É talvez visível neste processo deleuzoguattariano de criação um trabalho sobre a memória, como aquilo que está por detrás, mesmo em Derrida com a différance, o que aproximaria estes dois modos de pensar o corpo e o teatro/performance, mas não. Encontramos nestas duas filosofias, realmente, um aspecto de grande cariz intensivo, uma presença fulgurante, quase explosiva, de vida, de estar vivo através da criação e vida do que é criado. Mas enquanto na différance, tanto na produção como na recepção, subjaz um trabalho activo da memória, mesmo inconsciente ou sempre inconsciente embora implicando um trabalho, em Deleuze e Guattari a memória pouco influi na criação, a produção e a recepção é mais empírica e efabulatória. ${ }^{30}$ Nunca há trabalho sobre o passado, mas construção de presente, blocos de sensações sempre actuais, formas de devir-criança no presente:

É verdade que toda a obra de arte é um monumento, mas o monumento não é aqui o que comemora um passado, é um bloco de sensações presentes que só devem a si próprias a sua conservação, e dão ao acontecimento o composto que celebra. $\mathrm{O}$ acto do monumento não é a memória, mas a fabulação. Não se escreve com recordações de infância, mas por meio de blocos de infância que são formas de devir-criança do presente. (DELEUZE; GUATTARI, 2001, p. 148. grifo do autor).

30 BARTHES, 1989, p. 151. "A fabulação criadora nada tem a ver com uma recordação, ainda que amplificada, nem com um fantasma. [...] Trata-se sempre de libertar a vida lá onde ela é prisioneira, ou de o tentar num combate incerto". 
Mas então o que são os afectos e os perceptos? "Os afectos são precisamente esses devires não humanos do homem, como os perceptos (incluindo a cidade) são as paisagens não humanas da natureza" (DELEUZE; GUATTARI, 2001, p. 149). Para que os devires surjam na escrita é necessário que o próprio escritor devenha-outro. O estilo, que tanto Barthes (1989) como Deleuze consideram importante na relação do indivíduo com a língua, é uma linguagem de sensações, o trabalho que nele aparece é, primeiramente, um trabalho do corpo no sentido de soltar as tensões e agir sobre as flexões. Liberta-se o corpo para se libertar a língua, há um devir físico antes do devir das palavras (o devir que caracteriza as personagens, as figuras estéticas deleuzo-guattarianas). ${ }^{31}$

Existe de facto uma diferença entre as "palavras" do corpo e as palavras que se escrevem, mas essa diferença nasce da repetição das palavras. A passagem do corpo à literatura não é tanto uma questão de criação mas antes de repetição. A repetição não cria o "mesmo" ou o "semelhante" do autor na obra, não é o seu corpo ou o seu espírito que se encontra no bloco de sensações, mas um outro corpo, aquele que ele veio a ser através dos devires. A arte, como meio entre o corpo e outra coisa, é essa repetição. Arrancar as percepções e afecções é repeti-las, repetir o núcleo das experiências, mas são diferentes porque passam agora por outro corpo como perceptos e afectos. ${ }^{32} \mathrm{~A}$ repetição ajuda a destrinçar as possibilidades do corpo e da língua, as suas flexões, as suas tensões e o estilo. A repetição inaugura a diferença. É nesse sentido, por exemplo, que um bloco de sensações, como o bloco de infância, é diferente das memórias vividas. Podem repetir-se as memórias de infância mas, inseridas na linha de fuga de um deviroutro, passando pelo $\mathrm{CsO}$, essas memórias serão outras, serão diferentes.

Tal como o escritor também o actor/performer passa por um deviroutro, esse que indicámos como corpo virtual no cruzamento entre a partitura física e o texto (qualquer que ele seja, de um autor ou palavras soltas retiradas do quotidiano, etc.). Buscar as percepções e afecções para trazer os perceptos e afectos é produzir esse devir, aliás, os afectos são já devires, e a "escrita" de uma partitura física depende de um devir. Mas então o que é um devir? Devir

31 DELEUZE, 2001, p. 20. "Se a linguagem imita os corpos, isso não é devido às onomatopeias mas à flexão. E se os corpos imitam a linguagem, não é pelos órgãos, mas pelas flexões. Há toda uma pantomima interior à linguagem, como há um discurso, uma narrativa interior aos corpos. Se os gestos falam é porque, antes de mais, as palavras mimam os gestos."

32 DELEUZE, 2002, p. 25. "É na linguagem, no seio da linguagem, que o espírito capta o corpo, os gestos do corpo, como objecto de uma repetição fundamental. É a diferença que dá a ver os corpos e os multiplica; mas é a repetição que faz falar e autentifica o múltiplo, fazendo dele um acontecimento espiritual." 
não é, segundo Deleuze e Guattari, "atingir uma forma (identificação, imitação, Mimésis [sic]), mas encontrar a zona de vizinhança, de indiscernibilidade ou de indiferenciação tal que já não nos podemos distinguir de uma mulher, de um animal ou de uma molécula: não imprecisos nem gerais, mas imprevistos, nãopreexistentes, tanto menos determinados numa forma quanto mais singularizados numa população" (DELEUZE, 2002, p. 11-12) ${ }^{33}$ Normalmente toma-se este conceito relacionando-o com questões de correspondência físicas entre o homem e o animal, numa seriação de analogias e homologias, ou mesmo psíquicas, de imaginação (arquétipos ou fantasmas). Quando Deleuze e Guattari falam de devir, trata-se de uma coisa real, é um "entre" real. O homem não imita nem é, nem se torna realmente num animal (no caso de um devir-animal), mas está "entre" o homem e o animal.

$\mathrm{O}$ devir é o que o verbo significa, vir a ser. $\mathrm{O}$ devir surge entre a relação de um colectivo com uma anomalia (não no sentido de anormalidade, mas aquilo que foge, que traça um caminho), um conjunto de afectos, como um limite da multiplicidade. É entre essa relação que o Homem começa a sentir de outra forma, dissolvendo o seu "eu" através da abstracção, através da consciência do corpo, começa a devir-outro, a percorrer a linha do anómalo da sua própria multiplicidade onde habitam perceptos e afectos. Ao percorrer essa linha, que ao mesmo tempo o percorre, o indivíduo vive essas "novas" sensações (que afinal já eram suas), como que se divide. O actor/performer está ali, com as suas sensações e fluxos, mas como se abstrai, isto é, concentra-se no que o envolve e na produção que se encontra a realizar, vive um outro de sensações.

A repetição de sensações vividas abre o espaço da diferença entre nós e outro-nós, e essa diferença estabelece a distância entre nós e nós sem que haja real alienação do sujeito (embora certas performances que implicam a repetição tomam contornos de pura alienação do sujeito, por exemplo as danças Dervish ou performances de auto-mutilação). Mas esta é a própria noção de identidade que temos vindo a esclarecer, nunca somos um "eu", estamos continuamente a devir-outro através das experiências, da interacção com os outros, estamos sempre sobre a acção da différance. ${ }^{34}$

33 Não faremos uma análise rigorosa e extensa do devir no homem. Para uma leitura mais atenta deste conceito, vd. DELEUZE; GUATTARI, 1997; vol. IV, p. 12-113. Para um estudo de como funciona o devir, vd. GIL, 1987.

34 NANCY, 2000, p. 29. "Porque ele é outro-e porque a alteridade consiste no ser-tal, no semfim do ser tal e tal e tal deste corpo, exposto até às extremidades. O corpus inesgotável dos traços de um corpo". Sublinhado do autor. 
No fundo, o que diferencia este devir do devir "artístico", esse que surge na escrita, na música, na pintura, etc., depende de uma vontade (vontade de poder nietzscheano talvez), de uma intenção de trabalhar sobre as sensações, sobre nós e sobre a língua. É nesse sentido que devir-outro, (re)viver as sensações que nos percorrem, "não é sentir o outro nem absorvê-lo na maneira pessoal de sentir. Somos nós que nos moldamos ao objecto, sem que por isso - e é aqui que reside a dificuldade - nos percamos nele; o sentir-outro não abole a diferença, aprofunda-a, estabelece até como tal a partir de um moldar de formas (como a água e a esponja)" (GIL, 1987, p. 154).

O devir-outro, segundo o filósofo português, implica uma aprendizagem, é necessário passar primeiro por um devir-si próprio, uma análise sobre si. Devir-si próprio compreende duas componentes que se ligam, uma, que concerne o trabalho da consciência sobre as sensações, isto é, "um modo de sentir através da consciência de todos os outros modos de sentir" (GIL, 1987, p. 156), outra, que respeita a construção de um estilo, a maneira de tratar a língua que permite o conhecimento das várias sensações que nos povoam, a maneira de expressar esses outros modos de sentir. O devir-si próprio é, então, a construção de uma singularidade no seio da multiplicidade que somos constituídos, que potencia o devir-outro e todos os devires.

O devir-outro é, portanto, uma coincidência com outras sensações que seguimos, que nos percorrem, uma transformação da consciência nessa sensação com a dissolução do "eu", construção de um corpo de consciência (physis-psyché, CsO), fabricação de uma singularidade, viver esse novo modo de sentir e exteriorizá-lo pela escrita, por exemplo, ou na criação desse corpo virtual que indicámos.

\section{Conclusão}

Talvez toda esta nossa análise não responda à questão que a nós é principal. Delineámos alguns conceitos mas nunca chegámos a clarear a dúvida. Contudo, respondendo ou não às prerrogativas de um artigo analítico ou crítico, parecendo ao invés que vagueámos ao redor da questão, julgamos que fazemos jus à declaração inicial, isto é, para já o nosso interesse é o de suscitar o debate, o diálogo - dizendo-nos numa cena entre actores - mais do que estabelecer uma posição de poder afirmando acintosamente argumentos de uma investigação para nós apenas agora aberta. 
Há de facto uma alteração no corpo do actor/performer que pode ser imperceptível, que se pode esquivar ao olhar fascinado pela ostentação cénica ou por um grande número de participantes, e essa mudança no corpo não deve apenas a uma técnica, ao desenvolvimento de uma técnica (e muito menos a um dom ou inspiração). O corpo do actor/performer é tão banal quanto o do espectador - e nenhum dos corpos é banal - todavia um deles é assombrado por um fantasma, como dissemos anteriormente. Existe, pois, a técnica, contudo esta não é mais do que uma ferramenta para acordar e manter despertos os poderes de um corpo, que a qualquer momento pode ser largada, suprimida, esquecida, deixando o corpo livre a percorrer a sua própria linha guiando-o sempre a um novo corpo até ao fantasma (o que é e pode vir a ser).

Pensamos que o aprofundamento dos conceitos expostos ao longo deste artigo - aprofundamento esse procurado na aproximação entre a teoria (filosófica e teatral/performática) e a prática (de encenadores e actores/ performers) - poderão clarificar a leitura complexa desses mesmos conceitos, bem como promover um discurso cada vez mais fundado e apoiado do empirismo, por vezes demasiado metafísico, das concepções teatrais/ performáticas.

Para terminar gostaria de citar um romancista e ensaísta japonês, Junichiro Tanizaki, que, no seu ensaio sobre a estética da sombra, relembra uma noite em que assistia a um espectáculo Nô e é surpreendido pelas mãos de um actor, realçando o salto diferencial entre corpos:

Eu olhava aquelas mãos, depois transferia o olhar para as mãos, pousadas nos joelhos. Se essas mãos pareciam belas, isso provinha certamente do delicado movimento que as animava do pulso até à ponta dos dedos, e também da disposição, supremamente estudada, dos próprios dedos; todavia, persistia em mim uma dúvida: de onde poderia provir aquele esplendor da pele, que parecia emanar de uma fonte interior de irradiação? Pois quê, eram mãos japonesas das mais vulgares, e de facto, quanto ao tom da pele, em nada se distinguiam das minhas próprias mãos, ali sobre os meus joelhos! Duas, três vezes comparei com as minhas mãos de Kongô no palco à minha frente, mas por mais que as comparasse essas mãos eram sempre idênticas. E, coisa estranha, apesar disso essas mãos que no palco adquiriam uma beleza quase inquietante, nos meus joelhos eram apenas mãos banais. (TANIZAKI, 1999, p. 40-41). 


\section{Referências}

BARBA, E. A canoa de papel. São Paulo: Hucitec, 1994.

BARBA, E.; SAVARESE, Nicola. A dictionary of theatre anthropology: the secret art of the performer. $5^{\text {th }}$ ed. London, New York: Routledge, 2004.

BARTHES, R. O grau zero da escrita. Lisboa: Edições 70, 1989. (Coleções Signos).

CULLER, J. Sobre la deconstrucción. Madrid: Cátedra, 1984. (Coleção Crítica y studios literarios).

DELEUZE, G. Nietzsche e a filosofia. 2. ed. Porto: Rés, 2001. (Coleção Biblioteca de filosofia).

Crítica e clínica. Lisboa: Edições do Século XXI, 2002. (Coleção Biblioteca do pensamento contemporâneo fundamentos).

DELEUZE, G.; GUATTARI, F. O que é a filosofia? Lisboa: Editorial Presença, 1992. (Coleção Biblioteca do pensamento contemporâneo fundamentos).

Mil Platôs. (1995-1997). São Paulo: Editora 34, 1997.

. O Anti-Édipo, capitalismo e esquizofrenia. Lisboa: Assírio \& Alvim, 2004. (Coleção Peninsulares).

DERRIDA, J. Margens da filosofia. Porto: Rés, 1986.

A voz e o fenómeno. Lisboa: Edições 70, 1996. (Coleção Biblioteca de filosofia contemporânea).

Gramatologia. 2. ed. São Paulo: Perspectiva, 2004. (Coleção Estudos).

GIL, J. Fernando Pessoa ou a metafísica das sensações. Lisboa: Relógio d'Água, 1987. (Coleção Filosofia).

Metamorfoses do corpo. 2. ed. Lisboa: Relógio d’Água, 1997. (Coleção Antropos).

Movimento total: o corpo e a dança. Lisboa: Relógio d'Água, 2001. (Coleção Antropos).

NANCY, J.-L. Corpus. 2. ed. Lisboa: Veja, 2000. (Coleção Passagens). 
NIETZSCHE, F. A Genealogia da moral. 7. ed. Lisboa: Guimarães, 1997. (Coleção Filosofia \& ensaios).

OIDA, Y. L'acteur invisible. Arles: Actes Sud, 1997. (Coleção Le temps du théâtre).

TANIZAKI, J. O elogio da sombra. Lisboa: Relógio d'Água, 1999. (Coleção Antropos).

Recebido: 28/07/2008

Received: 07/28/2008

Aprovado: 05/08/2008

Approved: 08/05/2008 